\title{
A Musicoterapia no fortalecimento da comunicação entre os idosos institucionalizados
}

\author{
The Music Therapy in strengthening of \\ communication between the elderly institutionalized \\ La Musicoterapia en el fortalecimiento de la \\ comunicación entre los mayores institucionalizados
}

Ludgleydson Fernandes de Araújo

Leila Maria Sousa Santos

Edna de Brito Amaral

Anna Clara de Araújo Cardoso

Fauston Negreiros

RESUMO: O presente trabalho teve como objetivo investigar a musicoterapia como promotora do fortalecimento da comunicação entre os idosos institucionalizados de uma determinada Instituição de Longa Permanência do estado do Piauí. Utilizou-se a pesquisaação, como sendo o método intervencionista o qual permite a todos os envolvidos: o observar, a fim de se reunirem informações e se construir um cenário; o pensar, para explorar, analisar e interpretar os fatos; e, afinal, o agir, implementando e avaliando as ações. Os resultados mostraram que a musicoterapia entre idosos institucionalizados pode contribuir para o fortalecimento da comunicação, propiciando a sua socialização junto a profissionais e funcionários, além de consequentes sinais de recuperação da auto-estima. Assim, esses idosos descobrem, apesar da idade avançada, que habilidades e conhecimentos ainda podem ser adquiridos, como os de compor ou interpretar música, assim como verem estimulado seu exercício de habilidades físicas e mentais.

Palavras-chave: Musicoterapia; Idosos institucionalizados; Comunicação. 
ABSTRACT: The present work has as main objective to investigate the music therapy as a promoter in strengthening communication among institutionalized elderly in a given institution of long-stay. We used the action research as the interventionist method which allowed us to observe so that they could gather information and build a scenario; think, to explore, analyze and interpret the facts; and act, implementing and evaluating actions. The results showed that music therapy among institutionalized elderly can contribute to the strengthening of communication, providing socialization and signs of recovery of selfesteem, as they might find that despite the years, there are skills and knowledge that can still acquire, how to compose or play music, as well as stimulated the performance of physical and mental abilities.

Keywords: Musicoterapia; Institutionalized seniors; Communication.

RESUMEN: Este trabajo tuvo como objetivo principal investigar la terapia de la música como un promotor en el fortalecimiento de la comunicación entre los ancianos asilados en una institución en particular a largo plazo. Se utilizó la investigación-acción como el método intervencionista que nos permitió observar de modo que pudieran reunir información y construir un escenario; pensar, explorar, analizar e interpretar los hechos; y actuar, implementación y evaluación de las acciones. Los resultados mostraron que la terapia musical entre los ancianos asilados puede contribuir al fortalecimiento de la comunicación, proporcionando socialización y signos de recuperación de la autoestima, ya que fueron capaces de descubrir que a pesar de los años, hay habilidades y conocimientos que todavía puede adquirir, cómo componer o reproducir música, así como estimulado la búsqueda de las capacidades físicas y mentales.

Palabras clave: Terapia de música; Ancianos institucionalizados; Comunicación.

\section{Introdução}

Envelhecer é um processo natural no ser humano que vem sendo alvo de muitos estudos devido ao rápido crescimento da população de idosos. Apesar das várias dificuldades e problemas que aparecem nessa fase da vida deseja-se envelhecer em companhia de pessoas que favoreçam o diálogo, ou a capacidade de bem se relacionarem umas com as outras (Araújo, Amaral, \& Sá, 2014; Garrido, \& Menezes, 2002). 
Em decorrência de uma maior longevidade, são elaborados novos estilos de ser e estar nas etapas mais vitais da existência humana, "às quais gerações anteriores não afluíam ou, se a elas chegavam, apresentavam pouca qualidade de vida" (Mendes, 2012, p. 36).

É válido pontuar que os números relativos à população idosa vêm crescendo, acarretados por diversos fatores, dentre eles, a diminuição da taxa de fecundidade (Joia, \& Ruiz, 2013); esse aumento vem demandar uma grande variedade de formas de intervenções, como políticas específicas (Caballero, Lima, Costa, \& Galvis, 2013), bem como intervenções mais específicas às problemáticas que surgem e como se veem nas Instituições de Longa Permanência para Idosos (ILPs). Um exemplo de intervenções que podem ser realizadas com idosos, mostrando-se muito eficazes, é por meio da música, mais propriamente, da musicoterapia. Esta assume especial relevância no que diz respeito ao idoso, pois, ao estabelecer um canal de comunicação não-verbal por meio do som e da música, torna-se ferramenta valiosa de intervenção terapêutica para o idoso. A aplicabilidade dos recursos sonoros e musicais, na musicoterapia, tem como objetivo o estudo da relação íntima do som/música com o ser humano (Correia, Muskat, Vicenzo, \& Campos, 1998).

Assim sendo, pode-se refletir que o convívio social, por meio das redes de apoio social, e a aplicação de ferramentas de atuação, como as usadas na musicoterapia, vêm, como pontua Nasri (2008), motivar a conservação da saúde emocional das pessoas idosas. Isso se deve à criação de novos contatos sociais que possibilitam, além de apoio subjetivosocial, a garantia ao respeito, ao reconhecimento, à valorização, bem como ao sentir-se em uma rede de relações, fatores que superam as perdas físicas e sociais que comumente acontecem durante o processo de envelhecimento.

\section{As Instituições de Longa Permanência para Idosos}

Por definição, segundo o manual de funcionamento da Sociedade Brasileira de Geriatria e Gerontologia (SBGG, 2003), atualmente as ILPIs são estabelecidas para atendimento integral, institucionalizado, oferecendo cuidados a pessoas de 60 e mais anos, dependentes ou não, mas que não dispõem de condições para permanecer com familiares ou em seu domicílio. Essas instituições são conhecidas por denominações diversas: abrigo, asilo, lar, casa de repouso, clínica geriátrica ou ancianato. 
Essas instituições devem proporcionar serviços na área social, médica, psicológica, de enfermagem, terapia ocupacional, odontologia, entre outras, como por exemplo, a musicoterapia, conforme as necessidades desse segmento etário.

$\mathrm{O}$ atendimento é realizado em locais fisicamente adequados e equipados para proporcionar cuidados aos idosos, mediante pagamento, ou não, e durante um período indeterminado.

Esses locais devem reproduzir um ambiente residencial, mantendo as características de um lar. Não devem ser marcados pelo isolamento, pelo afastamento da vida urbana e familiar, nem ser espaço de uniformização da vida de seus usuários. Devem prever, na medida do possível, a participação dos usuários na qualidade individual dos ambientes, especialmente naqueles mais íntimos e reservados - os quartos, por exemplo.

Além disso, esse local deve fornecer o uso de elementos que atuem de forma positiva sobre a memória física dos idosos; para tal, devem promover uma relação de aprendizagem com o novo lar, com o novo espaço de moradia, de forma a incluir objetos que fossem capazes de resgatar antigos hábitos, experiências, recordações, fazendo com que o cotidiano atual do residente na instituição seja o mais parecido com o de sua antiga residência (Annunziato, 2007).

Hoje as ILPIs devem estar adaptadas e regulamentadas segundo as leis para manter o padrão mínimo de funcionamento. A ANVISA (Agência Nacional de Vigilância Sanitária, por meio da Resolução RDC n. ${ }^{\circ}$ 283, de 26 de setembro de 2005 (com publicação no D.O.U., Diário Oficial da União; Poder Executivo, de 27 de setembro de 2005), estabelece normas a serem aplicadas a todas as ILPIs, governamentais, ou não, destinadas à moradia coletiva, com ou sem suporte familiar.

Devem atender pessoas idosas independentemente do grau de dependência, e oferecer equipamentos especiais adequados à realização das atividades da vida diária (AVDs). A fim de manter uma assistência adequada quantos aos cuidados específicos para idosos, as ILPIs, segundo a (RDC, 2005), devem manter um quadro de profissionais, capacitados de acordo com as necessidades e exigências dos idosos ali residentes.

Pontue-se que as ILPIs estão cada vez mais em evidência e vêm se empenhando quanto à qualidade dos serviços prestados aos idosos. Seu objetivo não é substituir as famílias, mas garantir e proporcionar uma qualidade de vida satisfatória e digna aos idosos. 
Contudo, algumas instituições são carentes quanto a recursos financeiros, o que as leva a buscarem mão-de-obra não-qualificada na área gerontológica, por serem mais baratas, os chamados cuidadores informais, além de, em grande parte, manterem pouco ou nenhum contato com os familiares (Born, \& Boechat, 2013; Ferreira, 2008).

\section{Musicoterapia: necessária numa Instituição de Longa Permanência para Idosos}

Conforme Souza, Landrino, e Vianna (1988), o trabalho musicoterapêutico com idosos requer uma prática diferente daquela que é feita com outros pacientes, podendo-se trabalhar, principalmente, na modificação de seu comportamento se indesejado, e na ampliação de suas capacidades criativas. $\mathrm{O}$ tratamento musicoterapêutico oferece ao idoso a oportunidade de, num primeiro momento, estimular suas atividades mnêmicas, atingindo, a partir destas, outras funções cognitivas. Tocar ou manipular algum instrumento musical, cantar ou cantarolar músicas, fazer improvisos e compartilhar experiências, entre outras atividades, ajuda na elaboração de conteúdos mentais-cognitivos, inclusive os mais complexos, a partir da produção sonoro-musical (Souza, 1997). Além de estimular conteúdos mentais-cognitivos, a musicoterapia pode estimular as funções fisiológicas, interferido, por exemplo, no ritmo cardíaco, na respiração, e na pressão sanguínea, além de fortalecer e facilitar a movimentação do corpo (Blasco, 1999). Além disso, também afetar os aspectos emocionais, favorecendo a autoestima.

Passarini (2008) menciona a musicoterapia como uma nova área do conhecimento que, associada a exercícios terapêuticos, funciona como um importante papel no resgate e conservação da qualidade de vida de uma pessoa idosa. Contribui na prevenção e na reabilitação; favorece, por meio dos movimentos rítmicos, a diminuição e ou minimização das mudanças fisiológicas naturais da idade, o que é relevante no manejo com uma pessoa idosa.

Como enfatizam Mozer, Oliveira, e Portella (2011), a musicoterapia promove o desenvolvimento de potencialidades do idoso institucionalizado, e objetiva auxiliar o idoso das ILPIs no desenvolvimento de uma maior independência funcional; favorece melhora na qualidade de vida, sem muitos investimentos financeiros, dado que pequenas intervenções resultam em mudanças significativas na rotina de idosos das ILPIs, as quais contribuem, assim, para um processo de envelhecimento mais ativo. 


\section{Método e Procedimentos}

A musicoterapia objetiva desenvolver potenciais e/ou restabelecer funções do indivíduo para que este possa alcançar uma melhor qualidade de vida, por meio da prevenção, reabilitação ou tratamento específico (Passarini, 2008).

Antes de fazermos qualquer menção aos procedimentos metodológicos, ressaltamos que, neste estudo de pesquisa, os nomes dos envolvidos não foram citados, nem o local em que foram desenvolvidas as atividades, pois, apesar de termos desempenhado as práticas com o apoio e colaboração dos profissionais responsáveis pela instituição, o projeto não foi submetido ao Conselho de Ética.

Também evitaremos falar sobre o percurso da Instituição em foco, por não termos tido acesso a nenhum "escrito ou registro" de sua história, a não ser informações relatadas verbalmente pelos próprios funcionários.

$\mathrm{Na}$ instituição havia vinte e sete idosos - dez mulheres e dezessete homens. Destes, apenas dezessete aceitaram participar das atividades práticas - cinco mulheres e doze homens; quatro estavam acamados e seis rejeitaram participar.

Verificou-se, nos respectivos prontuários, que tanto suas histórias de vida, como suas capacidades mental-cognitivas, físicas e intelectuais, eram bem-diversificadas; estavam entre 62 e 92 anos, e o critério para participar do projeto foi estabelecido a partir de um desejo manifesto pelo próprio idoso - o de querer, ou não querer, participar.

Os instrumentos e materiais utilizados para este estudo de pesquisa foram: - dados biosociodemográficos dos idosos institucionalizados; - fichas musicoterapêuticas para apontar o histórico sonoro-musical de aceitação e rejeição do idoso; - testificação musical para comprovar, ou não, as informações do histórico sonoro-musical, assim como incluir informações outras, antes não mencionadas no referido histórico; - teste projetivo sonoromusical para verificar as reações do paciente em relação a determinadas músicas/sons/ruídos; - ficha musicoterapêutica para destacar a Identidade Sonora de cada idoso (ISO), - dados pessoais, habilidades artísticas; - relatórios diário e final. 
Outros dispositivos também são usados: toca-cd, CDs, bambolês, bolas, máquina fotográfica, gravador de voz, canudos, violão, claves, maracás, tambores, guizos, reco-reco, pandeiro, triangulo, bate-coco, microfone, caixa de som (estes dois últimos somente na comemoração do Natal), materiais reciclados (para confecção de instrumentos musicais e sonoros), bem como músicas de diversos gêneros (música erudita, forró universitário, e pé de serra, romântica, religiosa, sertaneja, e até repentes).

Em qualquer atividade de musicoterapia, há uma entrevista inicial com avaliação antes de iniciar as terapias; assim, se utiliza uma sala de entrevista e o setting de terapia.

No presente estudo, a entrevista foi realizada no "lugar" (espaço) onde se encontrava o idoso no momento da entrevista (quarto, pátio, refeitório ou outro). O setting de terapia foi o pátio do abrigo. O tempo das sessões e/ou das práticas musicoterapêuticas variou entre 40 minutos e 1 hora. Em algumas sessões fizemos aquecimento/alongamento corporal com a ajuda da fisioterapeuta do abrigo.

Ao finalizar as atividades, os idosos decidiam entre permanecer no pátio ou se retirarem. Contávamos com a ajuda dos funcionários da instituição, do início ao fim de cada atividade prática. Iniciávamos quando todos os participantes estavam plenamente acomodados no pátio; quando as atividades se concluíam, alguns preferiam permanecer no pátio, outros preferiam voltar para seus quartos e outros preferiam ficar na sala de TV.

A rotina semanal de terapias era de duas vezes por semana e. em algumas exceções, uma vez por semana.

O tempo de intervenção musicoterapêutica foi de três meses consecutivos, nos quais, se registraram fatores como assiduidade, boa participação e interesse pelas atividades, e raros casos de evasão do idoso, durante as mesmas.

Foram feitas gravações de voz (cantada e falada), registros fotográficos e escritos (relatórios), depoimentos, com a autorização dos responsáveis do abrigo e consentimento dos idosos. No início, recorremos a todas as informações adquiridas (entrevistas, testificações, relatórios, prontuários etc.). As entrevistas individuais ou o momento de "compartilhar experiências" eram feitas no final das atividades práticas, só que de forma dialogada (denominadas de relatos). As sessões eram divididas em três partes, conforme acontece em qualquer sessão de musicoterapia: $1^{\circ}$ aquecimento - diálogo, exercícios respiratórios e de alongamento; $2^{\circ}$ desenvolvimento - aplicação de técnicas musicoterapêuticas para a realização da terapia; $3^{\circ}$ fechamento/conclusão - preparação para o término da sessão e depoimentos (relatos) dos participantes. 
As sessões seguiam baseadas no modelo desenvolvido por Bruscia (2000). Normalmente, começavam com um rapport que consiste de uma atividade musical de saudação entre idosos e terapeuta. Depois disso, os idosos eram estimulados/provocados a se comunicarem através da via verbal ou não verbal (funcionando como um aquecimento terapêutico); em seguida, fazíamos a terapia do dia, utilizando uma das técnicas mencionadas antes, e finalizávamos com um novo diálogo para nos despedirmos. Em todas as sessões, utilizávamos instrumentos musicais e sonoros. Os objetivos trabalhados e suas respectivas técnicas foram: audição musical - para estimular a imaginação, a criatividade e provocar recordações e imagens no idoso; improvisação musical, para expressar espontaneamente por meio de qualquer instrumento musical, da própria voz (canto) e do próprio corpo (dança); canto e composição, para dialogar musicalmente (com repentes, por exemplo); re-criação, para utilizar a música (de ISO individual ou ISO grupal), para recriar outra letra que pudesse, também, igualmente à técnica anterior, gerar uma pergunta, admiração, negação, dúvida, raiva, amor, alegria, tristeza.

Pontua-se que, na época de realização da pesquisa, não havia comitê de ética em pesquisa na UFPI; todos os critérios éticos, porém, foram seguidos pelos pesquisadores, critérios estes estabelecidos pela Resolução n. ${ }^{\circ}$ 196/1996 do CNS/MS.

\section{Resultados}

A significação musical no contexto musicoterapêutico pode ser compreendida, analisada e interpretada, principalmente, a partir do sonoro (verbal ou "musical e não musical"), do movimento corporal e do tempo (momento de cada idoso ao longo de sua história). Na prática da musicoterapia, esta compreensão é fundamental.

Neste estudo como, por exemplo, para conhecer o idoso (o momento de anamnese no processo musicoterapêutico), lançamos mão deste recurso que nos permitiu conhecê-lo a partir das narrativas construídas sobre sua história de relação com a música. Também com esta compreensão, foi possível aproximar-nos, de forma mais coerente, de seus significados e sentidos, a partir do modo como vivenciava a atividade e a experiência musical no contexto musicoterapêutico. Cumpre lembrar que, para esta compreensão, levamos em conta a leitura da música e a dimensão afetiva do contexto em que o idoso encontrava-se situado (abrigo). 
Ou seja, não bastou que a musicoterapeuta fizesse análises musicais centradas apenas em partituras, para conhecer a relação do idoso com a música, e como isso se dava em sua vida, mas foi necessário que se articulasse, nessa análise, a dinâmica entre significados e sentidos construídos na história de vida dos idosos, plenamente situados em um contexto. Assim, pudemos entender que os idosos construíram seus significados da música em suas vivências afetivas, objetivando (consciente e/ou inconscientemente) suas subjetividades e, tornando-as audíveis para si mesmos e para os outros.

A partir das manifestações sonoro-musicais dos idosos, foi possível observar e trabalhar as condutas que possivelmente retratam as características psicológicas do grupo e/ou individualmente de cada idoso, que foram observadas fora do setting musicoterapêutico, nos primeiros dias de visita ao abrigo, ou em contato direto com os idosos, antes das atividades práticas. Dentro do setting musicoterapêutico, as características se manifestavam principalmente durante o momento do fazer musical (considerando toda e qualquer ação realizada), junto com o grupo que, igualmente, retratava seus aspectos psicoafetivos. Estamos considerando, aqui, toda a conduta expressa dentro do setting, quer fosse verbal ou não verbal, visto que estas transmitem as mensagens intrapsíquicas do sujeito idoso. Assim, destacamos:

Quadro 1 - Síntese das características musicoterapêuticas percebidas no grupo

Características psicológicas e/ou aspectos psico-afetivos, principalmente, antes das atividades musicoterapêuticas

- Não conversavam uns com os outros (grande maioria);

- Tinham intrigas entre eles;

- Poucos se conheciam;

- Eram mal-humorados;

- Pareciam solitários;

- Não sabiam os nomes uns dos outros (embora passassem horas sentados uns próximos aos outros);

- Alguns eram apelidados;

- Alguns eram agressivos (verbal e fisicamente);

- Tinham o hábito de faltarem com a verdade.
Condutas que apresentaram musicalmente dentro do setting musicoterapêutico

- Ao manusearem os instrumentos musicais apresentavam intensidade sonora muita elevada (ff);

- Preferiam os instrumentos sonoros que promovesse maior intensidade sonora (ex.: tambor);

- Apresentavam ritmos desestruturados ou desordenados;

- Apresentavam intensidade vocal alterada (quase inaudível em alguns; ou com bloqueios em outros, ou com muita pressa em outros; ou, ainda, com muita lentidão em outros);

- Quebravam e "furtavam" instrumentos musicais e objetos sonoros;

- Fugas do setting musicoterapêutico por incomodarem-se com a presença de outro idoso. 
Acreditamos que essas condutas apresentadas pelos idosos, inicialmente, eram caracterizadas, principalmente, "pela ausência de comunicação" entre eles (Silva, 1996).

Complementando a reflexão, Machado (1986, p. 25) afirma que:

Para entendermos o que está sendo dito por trás de um gesto agressivo, para entendermos o que realmente ele simboliza, precisamos escutar o inconsciente. Escutar o que está ali, armando relações, mas escondido, oprimido, negado, e que, por isso, sai no chute, na explosão, no tapa. Porque não está dando para falar. [...] numa situação agressiva; o que existe, de fato, é um comportamento a ser decifrado [...].

O idoso que bate, cospe, empurra, ou chuta, usa esse recurso porque não dispõe de outro - a palavra. E tais "recursos" acabam lhe sendo muito prejudiciais, porque ele sabe de antemão que tais atitudes seriam certamente reprovadas.

É fundamental que o musicoterapeuta tenha uma compreensão sobre em que ponto está musicalmente o idoso, qual seu alcance, para que se possam abrir os canais de comunicação, antes de qualquer outro objetivo. Tal compreensão ajudará no alcance do pretendido objetivo, considerando-se que a comunicação não verbal é projetada nas expressões não verbais através da musicalidade, a qual se expressa pelo corpo e por meio de instrumentos sonoros (Barcellos, 1998).

A musicoterapia e o fortalecimento da comunicação no contexto do idoso institucionalizado permitiram oportunizar um espaço de ressignificação da fala, da escuta e da capacidade comunicativa dos idosos envolvidos na pesquisa. Também foi possível promover uma relação mais íntima entre expressão sonora e corporal, inclusive de conteúdos intrapsíquicos. Como afirma Cianciarullo (1996), a comunicação como processo colabora com a qualidade dos relacionamentos. Por outra parte, Kron, e Gray (1989) destacam que a comunicação é mais do que apenas dizer palavras. Ela está presente em todas as nossas atividades cotidianas e relações pessoais. Observamos, nas sessões de musicoterapia, como a música se desenvolve, como é integrada, e como a comunicação verbal e não verbal se faz dentro do contexto musicoterapêutico. Nesse sentido, a musicoterapia além de promover ganhos na comunicação ajudou na estabilidade emocional; facilitou a auto-expressão, e a integração social dos idosos. 
Estimulou-se a criatividade dos idosos a partir do momento que eles passaram a fazer composições durante e após as atividades terapêuticas; também foi um meio importante para preencher vazios, por exemplo, quando receberam a visita das crianças de uma determinada escola municipal e relataram terem se sentido amados e valorizados ao ouvirem as crianças cantar, ao conversarem e serem ouvidas por elas - pois em troca cantaram-lhes suas composições. Além disso, foi possível o contato e o exercício da comunicação entre duas gerações diferentes. Os resultados mostraram que houve quebra de paradigmas, mudanças na convivência dos idosos, sendo que antes eles não se conheciam e nem conversavam. Interpretamos que estas mudanças, foram mudanças positivas nas relações entre esses idosos, que demonstraram, a partir daí, mais motivação para viver a vida. Como diz um dito popular, "Quem canta seus males espanta", a musicoterapia, por meio da relação terapeuta-idoso, e se valendo da música como forma de expressão, auxiliou esses idosos, para que despertassem e pudessem expressar, cantando e tocando, suas dores, angústias, medos, seus sonhos, seus desejos, construindo e experimentando um novo mundo de significados.

Acreditamos que a musicoterapia proporcionou um espaço diferenciado de escuta e de acolhimento, contribuindo na melhora da auto-estima, do autoconhecimento, estimulando a criatividade, a autoconfiança, desenvolvendo habilidades de socialização e comunicação, diminuindo a ansiedade, permitindo a melhora da qualidade de vida dos idosos e o fortalecimento da comunicação entre eles. Não sem razão Côrte, e Lodovici Neto (2009, s/págs.) afirmaram a respeito do trabalho com musicoterapia:

(...) um interlúdio muito significativo de Oliver Sacks: "O poder da música para integrar e curar [...] é fundamental. Ela é o mais profundo medicamento não-químico [...]", ao qual acrescentamos nosso poslúdio: a musicoterapia é o mais essencial dos processos terapêuticos, levando a pessoa afetada por uma doença(...), a manter uma posição "resiliente" diante da vida, ao minimizar a sintomatologia motora e não-motora, a transformar-se, a si mesma, diante da doença, sobrepondo-se a seus efeitos, ganhando força até para estancá-la em sua progressão, além de conseguir mudanças significativas até em outros companheiros. Tudo isso porque a musicoterapia possibilita que a pessoa orquestre mente, corpo e coração, resgatando sua identidade sonoro-musical. Em suma, a musicoterapia faz o indivíduo colocar-se na posição de maestro de sua própria vida e da vida de muitas outras pessoas. 


\section{Considerações Finais}

O presente estudo de pesquisa abordou a ILPI, o idoso institucionalizado, e a musicoterapia como promotora do fortalecimento da comunicação entre idosos. Verificamos que o idoso em instituição de longa permanência é uma realidade marcante no envelhecimento e, que tal instituição para idosos pode tornar-se um ambiente gerador de múltiplos significados, na verdade, um sistema de significados. Assim, para compreendêlos é necessário observar, ter escuta, interpretar o comportamento e o sentir do idoso.

Prestar serviços multiprofissionais e desenvolver práticas variadas com o idoso institucionalizado significa valorizar o ser humano, inclusive, na dimensão do cuidado em uma relação entre pessoas. Por isso mesmo, levamos a musicoterapia até a referida instituição, objetivando o fortalecimento da comunicação entre os idosos, pois sabemos que a musicoterapia é um canal para a comunicação; portanto, uma ferramenta para a cidadania.

A música nos identifica, caracterizando-se como um meio de expressão natural do ser humano. Segundo a Federação Mundial de Musicoterapia, "a musicoterapia é a utilização da música e/ou de seus elementos constituintes, ritmo, melodia e harmonia, por um musicoterapeuta qualificado, com um cliente ou grupo, em um processo destinado a facilitar e promover comunicação, relacionamento, aprendizado, mobilização, expressão, organização e outros objetivos terapêuticos relevantes, a fim de atender as necessidades físicas, emocionais, mentais, sociais e cognitivas".

A musicoterapia, conforme evidencia este estudo de pesquisa, atuou na ILPI como um meio de expressão para os idosos ali residentes. Por meio da música, eles puderam encontrar a possibilidade de expressar sentimentos e conteúdos que eram silenciados pela solidão, pela timidez, pelo constrangimento, pela vergonha (conforme se pôde apurar dos registros nos prontuários).

Ouvir, tocar, cantar e refletir sobre as canções foram ações que permitiram que o idoso expressasse sua história e nomeasse seus sentimentos sem necessariamente ter que expor verbalmente suas vivências como, por exemplo, de solidão, do abandono em que viviam; permitiu que os sentimentos fossem elaborados indiretamente, sem que ele se sentisse exposto, invadido. 
Acreditamos que a decisão de enfocar a musicoterapia tanto no contexto verbal quanto no não-verbal tenha sido a contribuição desta pesquisa, visto que a literatura sobre essas modalidades comunicativas tende a explorar o potencial semântico de uma dessas modalidades e seu valor constitutivo ou secundário (pesquisas que contrastam textos acadêmicos e textos não acadêmicos, por exemplo), sem, no entanto, identificar as estratégias de acomodação entre as linguagens. A falta de trabalhos nesse sentido (pelo menos até a conclusão desta pesquisa) limitou a definição de categorias coesivas entre o verbal e o não-verbal.

Além dessa dificuldade, convém relatar outra que tivemos para tentar alcançar pesquisas sobre as ILPs do Estado do Piauí, bem como sobre o idoso institucionalizado. Em função das limitações apontadas, e do reconhecimento dos avanços da musicoterapia, percebemos a necessidade de investimento em pesquisas futuras que visem a objetivos semelhantes ou suplementares aos desta pesquisa.

\section{Referências}

Annunziato, M. P. H. L. (2007). Atividade Física com idosos em Instituições de Longa Permanência. São Paulo, SP.

Araújo, L. F., Amaral, E. B., \& Sá, E. C. N. (2014). Análise semântica da violência na velhice sob a perspectiva de estudantes de ensino médio. Revista Kairós Gerontologia, 17(2), 105-120. Recuperado em 20 dezembro, 2014, de: https://revistas.pucsp.br/index.php/kairos/article/view/21334/15624.

Barcellos, L. R. M. (1998). Apontamentos das aulas ministradas e orientação à monografia, no Curso de Especialização em Musicoterapia na Saúde Mental, EMAC/Universidade Federal de Goiás, Goiânia.

Blasco, S. P. (1999). Compêndio de Musicoterapia. Barcelona, España: Edições Herder.

Born, T., \& Boechat, N. S. A. (2013). Qualidade dos Cuidados ao Idoso Institucionalizado. In: Freitas, E. V., et al. Tratado de Geriatria e Gerontologia, 11311141. (Cap. 119). Rio de Janeiro, RS: Guanabara Koogan.

Bruscia, K. E. (2000). Definindo Musicoterapia. (2 ed.). Rio de Janeiro, RJ: Enelivros.

Caballero, M. O., Lima, M. P., Costa, J. J., \& Galvis, C. S. (2013). Adultos Idosos como Agentes. O Projeto W2P. Revista E-Psi, 3(1), 48-68. Recuperado em 10 dezembro, 20145, de: http://www.udip.porto.ucp.pt/sites/default/files/files/FEP/docs/Temas_em_ Psicologia_do_Envelhecimento_Vol_I.pdf.

Cianciarullo, T. (1996). Instrumentos básicos para o cuidar: Um desafio para qualidade da assistência. São Paulo, SP: Atheneu. 
Correia, C. M. F., Muszkat, M., Vicenzo, N. S., \& Campos, C. J. R. (1998). Lateralização das funções musicais na Epilepsia Parcial. Arquivos Neuro-psiquiátricos, 56(4), 70-75. Recuperado em 20 dezembro, 2014, de: http://www.revistaneurociencias.com.br/edicoes/2000/RN\%2008\%2002.pdf.

Côrte, B., \& Lodovici Neto, P. (2009). A musicoterapia na doença de Parkinson. Ciênc. Saúde Coletiva, 14(6), 2295-2304. Recuperado em 01 dezembro, 2014, de: http://dx.doi.org/10.1590/S1413-81232009000600038.

Ferreira, B. E. (2008). O conceito qualidade de vida inserido na atividade física: reflexão sobre concepções e evidências. Buenos Aires, Argentina: Revista Digital, 13(122). Recuperado em 01 dezembro, 2014, de: http://www.efdeportes.com/.

Garrido, R., \& Menezes, P. R. (2002). O Brasil está envelhecendo: boas e más notícias por uma perspectiva epidemiológica. Rev Bras Psiquiatr, 24(suppl.1), 3-6. Recuperado em 01 dezembro, 2014, de: http://dx.doi.org/10.1590/S1516-44462002000500002.

Joia, L. C., \& Ruiz, T. (2013). Satisfação com a vida na percepção dos idosos. São Paulo, SP: Revista Kairós Gerontologia, 16(6), 79-102. Recuperado em 10 dezembro, 2014, de: https://revistas.pucsp.br/index.php/kairos/article/viewFile/20023/14898.

Kron, T., \& Gray, A. (1989). Administração dos cuidados de enfermagem ao paciente: colocando em ação as habilidades de liderança. Rio de Janeiro, RJ: Interlivros.

Machado, M. C. (1986). Como lidar com a criança agressiva. Revista Nova Escola, 4. (Ano I). São Paulo, SP: Fundação Victor Civita.

Mendes, T. S. (2012). Envelhescentes e resiliência: sujeitos psicológicos como capital social. Passo Fundo, RS: RBCEH, 9(1), 35-45. Recuperado em 10 dezembro, 2014, de: file:///C:/Users/Dados/Downloads/2200-10954-1-PB.pdf.

Mozer, N. M. S., Oliveira, S. G., \& Portella, M. R. (2011). Musicoterapia e Exercícios Terapêuticos na qualidade de vida de idosos institucionalizados. Porto Alegre, RS: Estudos Interdisciplinares em Envelhecimento, 16(2), 229-244. Recuperado em 10 dezembro, 2014, de: http://www.seer.ufrgs.br/RevEnvelhecer/article/view/14348.

Nasri, F. (2008). O envelhecimento populacional no Brasil. São Paulo, SP: Einstein, 6(supl. 1), S4-S6. Recuperado em 10 dezembro, 2014, de: http://www.prattein.com.br/home/images/stories/Envelhecimento/envelhecimento_popu.pdf.

Passarini, L. B. F. (2008). A musicoterapia atuando na qualidade de vida do idoso institucionalizado - caminhando pela Psicogerontologia. Trabalho apresentado como conclusão do curso de extensão: Psicogerontologia, Fundamentos e Perspectivas.

Silva, M. J. P. (1996). Comunicação tem remédio: a comunicação nas relações pessoais em saúde. São Paulo, SP: Gente.

Sociedade Brasileira de Geriatria e Gerontologia, Seção São Paulo 2003. Manual de funcionamento para Instituição de Longa Permanência para Idosos (ILPI). São Paulo, SP.

Souza, M. G. C., Landrino, N., \& Vianna, M. T. (1988). Musicoterapia com a $3^{a}$ idade. Monografia da Graduação em Musicoterapia. Rio de Janeiro, RJ: Conservatório Brasileiro de Música, CBM. 
Souza, M. G. C. de. (1997). Reflexões teóricas sobre a musicoterapia. Fórum de Musicoterapia, promovido pela Associação de Musicoterapia do Estado do Rio de Janeiro, 1997. Recuperado em 01 dezembro, 2014, de: http://www.revistademusicoterapia.mus.br/wp-content/uploads/2016/11/3-Reflex\%C3\%A7\% C 3\%B5es-Te\%C3\%B3ricas-sobre-a-Musicoterapia.pdf.

Recebido em 30/09/2015

Aceito em 30/01/2016

Ludgleydson Fernandes de Araújo - Psicólogo, Doutor em Psicologia, Universidade de Granada, Espanha, Mestre em Psicologia Social, Especialista em Gerontologia, UFPB, Professor Adjunto I, Programa de Pós-Graduação em Sociologia (Stricto Sensu) e Departamento de Psicologia, Universidade Federal do Piauí, UFPI, Campus de Parnaíba, PI.

E-mail: ludgleydson@yahoo.com.br

Leila Maria Sousa Santos - Musicoterapeuta, Professora Bolsista-UESPI, Especialista em Gerontologia Social, UFPI, Capacitada em Neuromúsica, Argentina.

Edna de Brito Amaral - Graduada em Psicologia, Universidade Federal do Piauí, UFPI, Campus de Parnaíba, PI. Especialista em Gestão em Saúde, UESPI. Universidade Federal do Piauí, Departamento de Psicologia, Campus de Parnaíba, Av. São Sebastião, 2819, Parnaíba, PI, Brasil. CEP 64202-020.

Anna Clara de Araújo Cardoso - Graduanda em Farmácia, Universidade Federal do Rio Grande do Norte, UFRN.

Fauston Negreiros - Psicólogo. Professor Adjunto II do Programa de Pós-Graduação em Sociologia (Stricto Sensu) e do Departamento de Ciências Sociais da Educação e Desporto do Campus Ministro Reis Velloso, da Universidade Federal do Piauí. 